Egyptian

Orthodontic Journal

\title{
THREE DIMENSIONAL EVALUATION OF PHARYNGEAL AIRWAY CHANGES ASSOCIATED WITH MAXILLARY INCISORS PROCLINATION IN CLASS II DIVISION 2 USING CONE-BEAM COMPUTED TOMOGRAPHY
}

\author{
Eiman S. Marzouk ${ }^{1}$ and Ahmed R. EL Kalza ${ }^{2}$
}

ABSTRACT:

Objective: To evaluate whether the correction of the axial inclination of retroclined maxillary incisors in Class II division 2 cases might affect the pharyngeal airway size and volume using Cone-Beam Computed Tomography (CBCT) and the Invivo Dental software (Anatomage). Materials and Methods: Eighteen adult male Class II division 2 subjects were enrolled in this study (mean age $23.83 \pm 3.67$ years). Two CBCT scans were obtained for each subject; pretreatment and after completion of the maxillary arch leveling only. The pretreatment and post-leveling pharyngeal air way mean values (size and volume) were compared using the paired sample t-test. Results: The results showed statistically significant increase $(\mathcal{P} \leq 0.05)$ in all oropharyngeal airway measurements following maxillary dental arch leveling. There has been $9.53 \% \pm 1.45 \%$ raise in the oropharygeal airway volume. In addition the analyses of the pretreatment and post-leveling mandibular measurements revealed high statistically significant

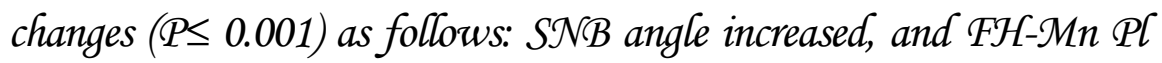
and $\mathcal{Y}$ axis-FH angles decreased, following the leveling of upper anteriors. Conclusion: The correction of the maxillary incisors inclination in Class II division 2 subjects improved the pharyngeal

1- Lecturer of Orthodontics, Faculty of Dentistry, Alexandria University, Egypt. 2- Lecturer of Orthodontics, Faculty of Dentistry, Alexandria University, Egypt. 
Egyptian

Orthodontic Journal

airway size and volume. This might be attributed to the anterior mandibular repositioning following the correction of upper incisors retroclination.

These findings are of valuable clinical importance, especially in cases of Class II division 2 with breathing problems due to pharyngeal constrictions.

\section{INTRODUCTION}

Angle $^{1}$ defined Class II division 2 malocclusion in 1907 as "the malocclusion characterized specifically by distal occlusion of the teeth in both lateral halves of the lower dentition, indicated by the mesiodistal relations of the first permanent molars, but with retrusion instead of protrusion of the upper incisors."

The morphological characterization of Angle Class II division 2 cases with retroclination of the upper incisors and the deep bite lead to a common belief that the mandible is displaced posteriorly in this type of malocclusion.

Several researchers ${ }^{2-4}$ reported that the mandible in Class II division 2 cases is in a distal relationship to the cranium and related the posterior position of the mandible to the muscular pressure against the maxillary central incisors and excessive closure of the bite. Godiawala and Joshi ${ }^{5}$ compared Class II division 2 and normal occlusion cases. They reported that the mandible in Class II division 2 was distinctly placed distally in males only. Moreover, Enany ${ }^{6}$ reported that the mandible was placed distally in Class II division 2 male subjects only when comparing Class I, II and III subjects. While Rostom, Zaher and El-Harouni ${ }^{7}$ presented a morphogenic description of the mandible in both Class II divisions. The authors reported that both Class II divisions showed a more retrusive mandibular position than normal.

It is believed that relatively short and/or posteriorly placed (retrognathic) mandible might force the tongue and the soft palate back into the pharyngeal space, narrowing the pharyngeal airway passage causing a reduction in oropharyngeal airway volume and increasing the 
Egyptian

Orthodontic Journal

likelihood of impaired respiratory function. ${ }^{8-10}$ Moreover, Class II patients showed smaller oropharyngeal airway volumes when compared with Class I and Class III patients. ${ }^{9}$ A retrognathic mandible which is often related to Class II malocclusions has often been reported in concurrence with obstructed sleep in children; and has been regarded as a predisposing factor for the development of obstructive sleep apnea. ${ }^{11-13}$

This causal relation between the mandibular backward position, retrognathism and reduced pharyngeal airway dimensions, explained why therapy targeting advancement of the mandibular position in Class II cases by functional appliances ${ }^{14,15}$ and mandibular advancement surgery ${ }^{16}$ has shown an increase in pharyngeal air way dimensions.

A number of authors ${ }^{17-21}$ deduce that the mandibular path of closure is influenced by the lingually inclined maxillary incisors and the deep bite; where the mandible is forced into a retruded position by the anterior teeth and the condyles are displaced posteriorly. It is a common belief that "unlocking" the mandible in Class II division 2 malocclusions allows correction of the distocclusion. ${ }^{22,23}$ Cleall and BeGole ${ }^{24}$ assumed that the correction of the deep overbite and proclination of upper incisors altered the distal mandibular shift in Class II division 2 cases, adding credence to the concept of freeing the mandible. Moreover, Gong and coworkers ${ }^{25}$ and Fathallah et al ${ }^{26}$ concluded that correction of the maxillary incisors retroclination in Class II division 2 deep-bite cases lead to a statistically significant change of the condylar position moving anteriorly and inferiorly. This might presume a correlation between the incisors retroclination, mandibular backward position and consequently the pharyngeal airway dimensions in Class II division 2 malocclusion.

Conversely other authors ${ }^{27-31}$ found no evidence to support that the mandible is "distally locked" and that the mandibular positions revealed no signs of anterior mandibular repositioning after proclination of the retroclined upper incisors during the treatment of Class II division 2.

Two dimensional imaging techniques using lateral cephalograms are used to evaluate changes in airway dimensions ${ }^{14-16}$. They are valuable but the complex anatomy of the airway is not fully appreciated except with 3-dimensional images. ${ }^{32}$ In addition, lateral cephalometric films 
Egyptian

Orthodontic Journal

have many limitations such as: image enlargement and distortion, structure overlap, limited identifiable landmarks and positioning problems that may adversely affect image quality. ${ }^{33}$

Compared with traditional Computed Tomography (CT) techniques, CBCT is a better method for airway volume measurement because of its lower cost, easier access, availability to dentists, X-ray beam limitation, image accuracy, rapid scan time, display modes unique to maxillofacial imaging, reduced image artifacts and much lower overall effective absorbed dose of radiation than CT. ${ }^{34,35}$ Besides, CBCT images can provide both two dimensional planner projections and three dimensional surface or volume rendered images. ${ }^{34,35}$

According to our knowledge the effect of the correction of retroclined upper anterior teeth on pharyngeal airway in adult Class II division 2 cases has not been discussed up till now. Moreover, the controversial data regarding the unlocking and forward shift of the mandible in Class II division 2 cases, prompted us to investigate whether change in the pharyngeal airway would be expected following the correction of the retroclined maxillary incisors in adult Class II division 2 cases.

\section{MATERIALS \& METHODS}

The sample size was estimated using a computer software ${ }^{36}$, it was determined that 14 subjects would be needed to conduct this study with a power of $90 \%$ at alpha $=0.05$.

Eighteen adult male Class II division 2 subjects (mean age was $23.83 \pm 3.67$ years) were enrolled in this study. All the included cases had Angle Class II molar and canine relationships with ANB angle $>3^{\circ}$, deep bite (more than 50\%), retroclined maxillary incisors and presence of contact between the palatal surface of the maxillary incisors and the labial surface of the opposing mandibular incisors. Subjects with obstructive sleep apnea, respiratory problems and those with repeated episodes of tonsillitis or adenitis were excluded from the study. All subjects were free from seasonal allergies, no systemic diseases that may affect the TMJ, no history of trauma or surgery to the TMJ, no history of previous orthodontic and/or orthopedic treatment, no upper respiratory operations 
Egyptian

Orthodontic Journal

(adenoidectomy, tonsillectomy) before or during treatment; and no clinically detectable functional shifts.

All recruited subjects were within the normal weight range [body mass index (BMI) $18.5-24.9 \mathrm{~kg} / \mathrm{m}^{2}$ at pretreatment] with no recent history of excessive weight fluctuations and not undergoing weight altering diets at the time of treatment.

The subjects were treated at the Department of Orthodontics, Faculty of Dentistry, Alexandria University. A written informed consent was obtained from each subject before enrollment in the study. Ethical committee of Faculty of Dentistry, Alexandria University, approved the ethical concerns of this study.

All patients were treated with a non extraction protocol using 0.022 X 0.028 inch preadjusted appliances. The maxillary arch leveling started by 0.014 inch nitinol continuous arch wires progressing up to $0.019 \times 0.025$ inch stainless steel wires.

Two CBCT scans were obtained for each subject, one before the start of the treatment (pretreatment) and the second immediately after completion of the leveling stage of the maxillary arch only (post-leveling). A built in Laser beam and the device cephalostat were used to orient and standardize the subject's head for reproducibility of the two scans. Patients were instructed to occlude in maximum intercuspation throughout the scan. ${ }^{37}$ All scans were obtained using Galileos comfort, Sirona, Germany. The device performs volumetric study with a view field of $15 \times 15 \times 15 \mathrm{~cm}$, delivering a dose of $75 \mu \mathrm{Sv}$, at $85 \mathrm{KV}, 5-7 \mathrm{~mA}$ in around 14 seconds. The same machine settings were adjusted by the same operator before each scan to ensure the standardization. DICOM files were obtained on the workstation (Galaxis 1.9, Sirona dental technology, Germany) the data was acquired with $0.3 \mathrm{~mm}$ slice thickness, with a resolution of $1024 \times 1024$ image matrix and $0.3 / 0.15 \mathrm{~mm}$ isotopic voxel size. The patient's DICOM file was loaded into the Invivo Dental software (Anatomage, San Jose, Calif.), volumetric imaging software for three-dimensional volumetric airway analysis. 
Egyptian

Orthodontic Journal

The landmarks and measurements used are shown in Table 1 and Figures 1-3. The linear pharyngeal airway size measurements were modifications based on the methods described previously by Lowe et $\mathrm{al}^{38}$ and Zhong et al. ${ }^{39}$

To obtain the angular and linear measurements for this study; 2-dimensional lateral cephalometric radiographs were obtained from the 3-dimensional $\mathrm{CBCT}$ data and the required measurements were obtained using the angular and linear measurement tools.

To define the oropharynx volume area of interest, the DICOM images obtained from CBCT scans were analyzed using Invivo Dental software (Anatomage). The total oropharyngeal airway volume was demarcated as the airway volume between two planes as shown in Figure 4. The superior plane was defined on the midsagittal image as the horizontal line through the posterior nasal spine extending to the posterior wall of the pharynx and the inferior plane was defined as the horizontal line through the superior point of the epiglottis extending to the posterior wall of the pharynx. ${ }^{40}$ Once segmentation was performed, the software automatically computed the volume of the oropharyngeal region (Figure 5). All the measurements of the study were performed by a blinded operator.

\section{STATISTICAL ANALYSIS}

Statistical calculations were carried out using Statistical Package for Social Sciences (SPSS/ version 17). The data were tested for normality by One-Sample Kolmogorov-Smirnov test; all the $\mathrm{P}$ values were greater than 0.05 , thus the data was judged as normally distributed. Besides descriptive statistics (mean, standard deviation), in order to test the statistical significance of the difference between the means of the pretreatment and post-leveling measurements of the variables, a paired sample t-test was used. Moreover, the absolute and percentage changes of the airway and mandibular position were calculated. The statistical significance level was established at $\mathrm{P} \leq 0.05$. 
Egyptian

Orthodontic Journal

To detect method error, randomly selected 10 CBCTs were measured a second time 15 days later by the same operator. The initial and the repeated measurements were compared using the paired t-test. The test did not show significant difference at the 0.05 level.

\section{RESULTS}

The sample consisted of 18 adult male Class II division 2 subjects with mean age $23.83 \pm 3.67$ years. The mean study duration (leveling procedure) was $5.26 \pm 1.43$ months. All included subjects were within the normal weight range; BMI 18.5-24.9 $\mathrm{kg} / \mathrm{m}^{2}$ with no excessive weight changes during the study.

The results (Table 2) displayed a statistically significant increase in all the airway measurements; PNS-R, SPP-SPPW, U-MPW, V-LPW, VAL and oropharygeal airway volume, following maxillary dental arch leveling; with a high elevation observed in the (SPP-SPPW) size and VAL $(\mathrm{P} \leq 0.01)$, and the oropharygeal airway volume $(\mathrm{P} \leq 0.001)$. There has been $9.53 \% \pm 1.45 \%$ raise in the oropharygeal airway volume following correction of the axial inclination of the upper anteriors.

Also the analyses of pretreatment and post-leveling means of the mandibular measurements revealed high statistically significant changes $(\mathrm{P} \leq 0.001)$ as follows: SNB angle and FH-Mn PL increased, while Y axis$\mathrm{FH}$ angles decreased following the leveling of upper anteriors. The mandibular measurement changes point to a forward and upward movement of the mandible after upper anteriors leveling.

Table 1. Landmarks and Measurements.

\section{Landmarks}

- Hor: Most inferior point of spheno-occipital synchondrosis.

- PNS: Posterior nasal spine.

- R: Point of intersection of line from Hor to PNS and posterior pharyngeal wall.

- SPPW: Point of intersection of line from soft palate center perpendicular to posterior pharyngeal wall. 
- SPP: Point of intersection of line from soft palate center perpendicular to posterior pharyngeal wall and posterior margin of soft palate.

- U: The tip of the uvula.

- MPW: Foot point of perpendicular line from point $U$ to posterior pharyngeal wall.

- V: The most postero-inferior point on the base of the tongue.

- LPW: Foot point of perpendicular line from point $\mathrm{V}$ to posterior pharyngeal wall.

- E: Epiglottis

\section{Measurments}

Upper airway size:

1) PNS-R (mm): Distance between PNS and R

2) SPP-SPPW(mm): Distance between SPP and SPPW

3) U-MPW(mm): Distance between U and MPW

4) V-LPW(mm): Distance between V and LPW

5) VAL(mm): Vertical airway length, distance between PNS and V

Oropharygeal airway volume $\left(\mathrm{cm}^{3}\right)$ : airway volume between horizontal line through the PNS and the inferior plane was defined as the horizontal line through the superior point of the epiglottis.

\section{Mandibular measurements:}

1) SNB angle

2) FH-Mn Pl angle: FH (Frankfort plane) defined by line passing through Orbital (Or) and Porion (Por). Mn (Mandibular plane) defined by line passing through Gonion (Go) and Gnathion (Gn).

3) $Y$ axis - FH angle: Mesial angle at the intersection of the $Y$-axis (S-Gn) and FH plane. 


\section{Egyptian \\ Orthodontic Journal}

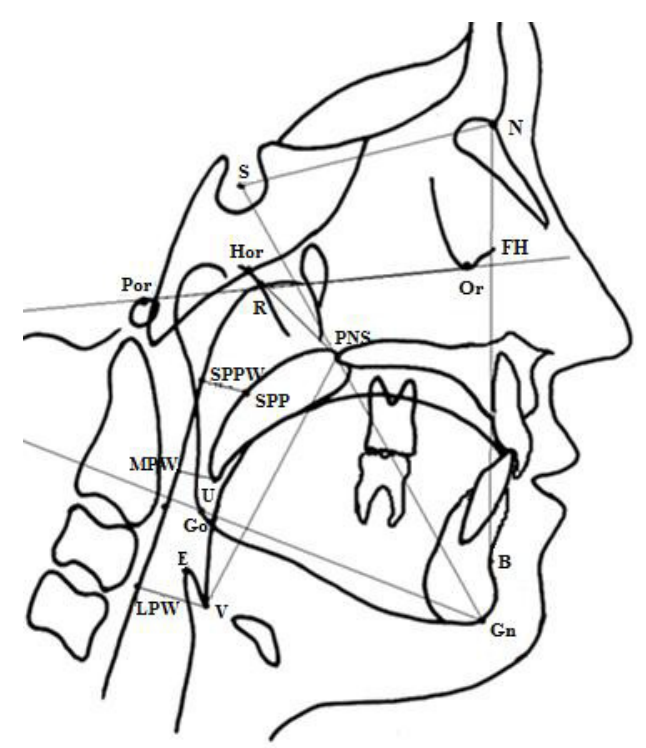

Figure 1. The landmarks and analyses of pharyngeal airway and mandibular position.

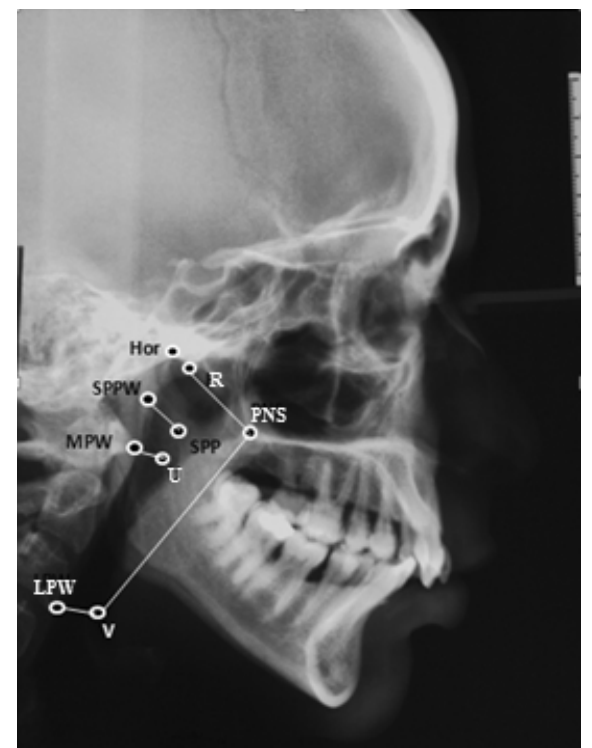

Figure 2. The pharyngeal airway linear analyses used in the study. 


\section{Egyptian}

Orthodontic Journal

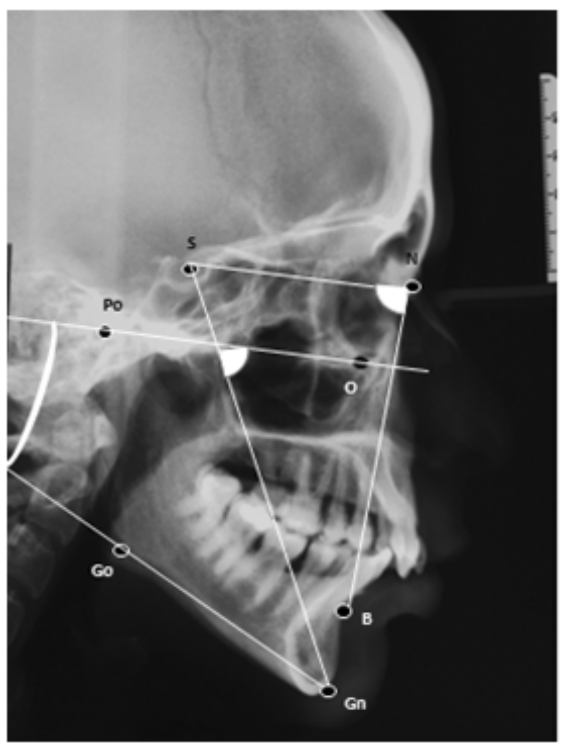

Figure 3. The mandibular angular measurements used in the study.

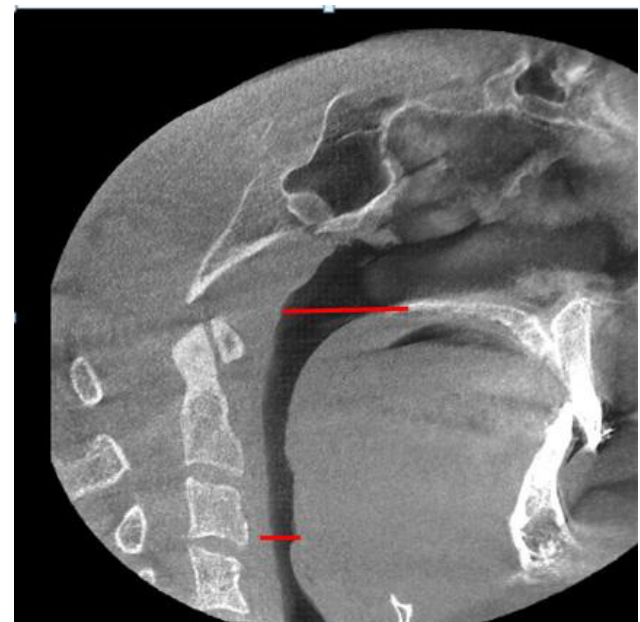

Figure 4. Midsagittal plane of a $\mathrm{CBCT}$ showing the limits of the oropharyngeal airway.

The superior border is the horizontal line through the posterior nasal spine extending to the posterior wall of the pharynx. The inferior border is the horizontal line through the superior point of epiglottis extending to the posterior wall of the pharynx. 


\section{Egyptian}

Orthodontic Journal

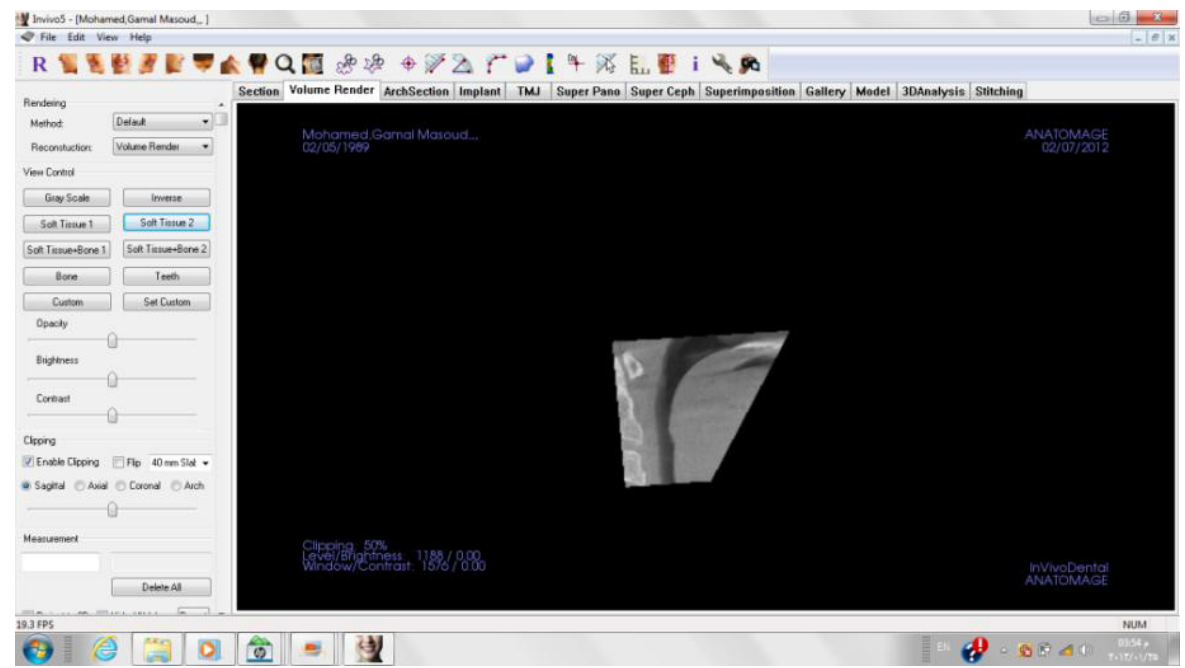

Figure 5. Midsagittal plane of a CBCT, showing segmentation of the area of interest for the oropharyngeal airway volume measurement, using the Invivo Dental software (Anatomage).

Table 2. Pretreatment and post-leveling Means, Standard Deviations, $P$ Values and Absolute and Percentage changes of the oropharyngeal airway and mandibular measurements.

\begin{tabular}{|l|c|c|c|c|c|}
\hline \multicolumn{1}{|c|}{ Measurements } & $\begin{array}{c}\text { Pretreatment } \\
(\mathbf{n = 1 8})\end{array}$ & $\begin{array}{c}\text { Post-leveling } \\
(\mathbf{n = 1 8})\end{array}$ & $\mathbf{P}$ & $\begin{array}{c}\text { Absolute } \\
\text { change }\end{array}$ & $\begin{array}{c}\text { Percentage } \\
\text { change }\end{array}$ \\
\hline Upper airway size & & & & & \\
\hline 1) PNS-R (mm) & $14.43 \pm 3.88$ & $15.97 \pm 3.06$ & $0.02^{*}$ & $1.54 \pm 1.56$ & $10.69 \pm 17.35$ \\
\hline 2) SPP-SPPW (mm) & $14.24 \pm 1.79$ & $15.51 \pm 1.88$ & $0.008^{* *}$ & $1.27 \pm 1.09$ & $8.91 \pm 7.83$ \\
\hline 3) U-MPW (mm) & $10.40 \pm 5.06$ & $12.13 \pm 5.67$ & $0.023^{*}$ & $1.73 \pm 1.85$ & $16.59 \pm 7.83$ \\
\hline 4) V-LPW (mm) & $10.95 \pm 5.11$ & $12.83 \pm 6.84$ & $0.029^{*}$ & $1.88 \pm 2.12$ & $17.17 \pm 10.06$ \\
\hline 5) VAL (mm) & $48.14 \pm 8.05$ & $50.44 \pm 7.23$ & $0.009^{* *}$ & $2.30 \pm 1.2$ & $4.78 \pm 4.99$ \\
\hline $\begin{array}{l}\text { Oropharygeal airway } \\
\text { volume (cm })^{3}\end{array}$ & $7.24 \pm 1.43$ & $7.93 \pm 1.51$ & $0.000^{* * *}$ & $0.69 \pm 0.12$ & $9.53 \pm 1.45$ \\
\hline Mandibular measurements & & & & & \\
\hline 1) SNB angle & $75.10 \pm 1.29$ & $76.60 \pm 1.26$ & $0.000^{* * *}$ & $1.5 \pm 0.53$ & $2 \pm 0.72$ \\
\hline 2) FH-Mn Pl angle & $31.60 \pm 1.17$ & $28.40 \pm 0.84$ & $0.000^{* * *}$ & $-3.2 \pm 1.32$ & $-10.03 \pm 3.89$ \\
\hline 3) Y axis- FH angle & $68.40 \pm 2.37$ & $62.20 \pm 1.81$ & $0.000^{* * *}$ & $-6.2 \pm 2.04$ & $-9.01 \pm 2.78$ \\
\hline
\end{tabular}

$* \mathrm{P} \leq 0.05, * * \mathrm{P} \leq 0.01, * * * \mathrm{P} \leq 0.001$ 
Egyptian

Orthodontic Journal

\section{DISCUSSION}

Our study addresses potential confounding factors. First of all, included subjects were all males to avoid any bias in results due to gender and they were all adults (mean age $23.83 \pm 3.67$ years) to eliminate the effect of growth on the air way measurements. All subjects were within the normal weight range (BMI 18.5-24.9 $\mathrm{kg} / \mathrm{m}^{2}$ ) with no excessive weight changes during the study, to exclude the effect of weight fluctuations on our results. A number of researches concluded that weight loss and decreased BMI are followed by an increased air way volume, reduction in sleep-disordered breathing and improvement in pharyngeal function. ${ }^{41,42}$ In addition subjects with seasonal allergies, adenitis or tonsillitis were excluded as it is known that the pharyngeal airway is liable to changes of dimensions due to hypertrophy of lymphoid tissues.

Moreover, ensuring the absence of functional shifts was to discard the idea that patients with functional shifts, might have shifted forward in the second CBCT -thereby opening the airway- as opposed to a true anterior movement resulting from the incisor proclination.

Up to our knowledge no other researchers studied the relation between the correction of upper insicors inclination and the change in the pharyngeal airway in Class II division 2 cases using three dimensional images (CBCT).

The selection of the CBCT technique was preferred to the conventional CT because of: its lower cost, easier access, availability to dentists, X-ray beam restriction, image accuracy, speedy scan time and lower effective dose. ${ }^{34,35}$ Moreover, the incorporation of the cephalostat and the laser beam in the CBCT machine ensured the accurate head positioning for accurate reproducibility of standardized scans.

The results of this study displayed a significant increase in all the airway measurements following the correction of the axial inclination of the retroclined upper anteriors, with a high statistical significant elevation especially observed in the (SPP-SPPW) size and VAL $(\mathrm{P} \leq 0.01)$ and the oropharygeal airway volume $(\mathrm{P} \leq 0.001)$. Our results might be attributed to the associated anterior functional displacement of the mandible after 
freeing its lock. This might be explained by the noteworthy increase in the SNB angle and decrease in FH-Mn $\mathrm{Pl}$ and $\mathrm{Y}$ axis-FH angles, indicating forward and upwards displacement of the mandible.

A number of authors ${ }^{17-19,21-23}$ agreed that deep-bite can cause posterior mandibular displacement, especially if combined with lingually inclined incisors, because the incisors can create interferences that cause a distal path of closure. Cleall and BeGole ${ }^{24}$ presumed that the correction of the deep overbite and proclination of upper incisors in Class II division 2 cases modified the path of closure of the mandible and aided in the correction of the Class II molar relation. Gong and colleagues ${ }^{25}$ also found that with the increase of inclination of upper incisors and bite opening; the mandibular condyles moved anteriorly and inferiorly. Recently, Sallam et al ${ }^{20}$ denoted posterior condylar displacement in Class II division 2 subjects with deep bite, minimal overjet and retroclined maxillary incisors. Lately, Fathallah et $\mathrm{al}^{26}$ reported that the correction of the maxillary incisors retroclination in Class II division 2 subjects showed statistically significant functional displacement of the condylar moving anteriorly and inferiorly.

On the other hand, many studies disagreed with our results. Pullinger et $\mathrm{al}^{28}$ found no correlation between incisal overbite, overjet and condylar position. Other studies ${ }^{30,31}$ found no significant evidence to support that the mandible is "distally locked" because of the maxillary central incisors angulations. Gianelly and coworkers ${ }^{29}$ did not believe that the correction of the overbite will allow the mandible to shift forward. However, they used corrected tomograms and the study did not directly test the effect of unlocking the bite on the condylar position on the same subjects rather they compared Class II with and without deep bite. In a study by Demisch, Ingervall and Thüer $^{27}$ the spontaneous anterior mandibular repositioning after proclination of the maxillary incisors was not validated. This might be because the appliance used for proclination of the upper incisors incorporated anterior bite plates leading to downward and backward rotation of the mandible, which might have cancelled the effect of the anterior mandibular repositioning. 
Egyptian

Orthodontic Journal

\section{CONCLUSION}

Based on the results from this study, the following conclusions can be inferred.

- The correction of the maxillary incisors inclination in Class II division 2 subjects improved the pharyngeal airway size and volume.

- This might be attributed to the anterior mandibular repositioning subsequent to the correction of the retroclined upper anteriors.

Studying the changes in the pharyngeal airway size and volume after upper anteriors leveling has valuable clinical implications, especially in cases of Class II division 2 with breathing problems due to pharyngeal constrictions. Moreover, the association between deep-bite with contacting incisors in relation to mandibular retro-positioning is of clinical importance, because it may affect the treatment strategies; whether to extract or not in the upper arch.

\section{REFERENCES}

1. Angle E. Treatments of Malocclusion of the Teeth. 7th ed. Philadelphia: S.S. White Dent. Mfg. Co.; 1907.

2. Strang R. Class II, Division malocclusion. Angle Orthod 1958; 28:210-4.

3. Kerr WJ, Hirst D. Craniofacial characteristics of subjects with normal and post normal occlusion- a longitudinal study. Am J Orthod Dentofac Orthop 1987; 92:207-12.

4. Brezniak N, Arad A, Heller M, Dinbar A, Dinte A, Wasserstein A. Pathognomonic cephalometric characteristics of Angle Class II Division 2 malocclusion. Angle Orthod 2002; 72:251-7.

5. Godiawala RN, Joshi MR. A cephalometric comparison between Class II, division 2 malocclusion and normal occlusion. Angle Orthod $1974 ;$ 44:262-7.

6. Enany N. Comparative study of condylar position and mandibular path of closure from rest position to final occlusion in normal, Class II and Class III Angle's malocclusion [Master Thesis]. Alexandria, Egypt: Alexandria University; 1975. 
Egyptian

Orthodontic Journal

7. Rostom T, Zaher A, El-Harouni N. Morphogenic description of the mandible in Angle's Class II malocclusion among Egyptians. [Master Thesis]. Alexandria, Egypt: Alexandria University; 2001.

8. Lowe AA, Santamaria JD, Fleetham JA, Price C. Facial morphology and obstructive sleep apnea. Am J Orthod Dentofacial Orthop 1986; 90:484-91.

9. El H, Palomo JM. Airway volume for different dentofacial skeletal patterns. Am J Orthod Dentofacial Orthop 2011; 139:e511-21.

10. Ozbek MM, Miyamoto K, Lowe AA, Fleetham JA. Natural head posture, upper airway anatomy and obstructive sleep apnea severity in adults. Eur J Orthod 1998; 20:133-43.

11. Guilleminault C, Stoohs R. Chronic snoring and obstructive sleep apnea syndrome in children. Lung 1990; 168: 912 -9.

12. Shintani T, Asakura K, Kataura A. Evaluation of the role of adenotonsillar hypertrophy and facial morphology in children with obstructive sleep apnea .ORL J Otorhinolaryngol Relat Spec 1997; 59: 286-91.

13. Kawashima S , Peltomäki T , Sakata H , Mori K , Happonen R-P , Rönning O. Craniofacial morphology in preschool children with sleep-related breathing disorder and hypertrophy of tonsils. Acta Paediatr 2002; 91: 71-7.

14. Jena AK, Singh SP, Utreja AK. Effectiveness of twin-block and Mandibular Protraction Appliance-IV in the improvement of pharyngeal airway passage dimensions in Class II malocclusion subjects with a retrognathic mandible. Angle Orthod 2013; 83:728-34.

15. Kinzinger G, Czapka K, Ludwig B, Glasl B, Gross U, Lisson J. Effects of fixed appliances in correcting Angle Class II on the depth of the posterior airway space: FMA vs. Herbst appliance-a retrospective cephalometric study. J Orofac Orthop 2011; 72:301-20.

16. Sahoo NK, Jayan B, Ramakrishna N, Chopra SS, Kochar G. Evaluation of upper airway dimensional changes and hyoid position following mandibular advancement in patients with skeletal class II malocclusion. J Craniofac Surg 2012; 23:e623-7. 
17. Ricketts R. Abnormal function of the tempromandibular joint and related musculature. Am J Orthod 1955; 41:435-41.

18. Owen AH 3rd. Orthodontic/orthopedic treatment of craniomandibular pain dysfunction. Part 2: posterior condylar displacement. J Craniomandibular Pract 1984; 2:334-49.

19. Thompson JR. Part II: Abnormal function of the temporomandibular joints and related musculature. Orthodontic implications. Angle Orthod 1986; 56:181-92.

20. Sallam R, El-Harouni N, Mousa H, Hamimi A. Positional and morphological characteristics of the tempromandibular joint in subjects with Class II division 2 malocclusion [Master Thesis]. Alexandria, Egypt: Alexandria University; 2012.

21. Kaddah M. Condylar position in Class II Division 2 malocclusion: A CT study. Cairo Dental Journal 1996; 12:261-8.

22. Taylor AT. Release mechanisms in the treatment of Class II, Division 2 malocclusions. Aust Dent J 1966; 11:27-37.

23. Ricketts R, Bench R, Gugino C, Hilgers J, Schulhof R. Bioprogressive Therapy Book 1. 2nd ed. Denver: Rocky Mt. Orthod; 1979:183-99.

24. Cleall JF, BeGole EA. Diagnosis and treatment of Class II division 2 malocclusion. Angle Orthod 1982; 52:38-60.

25. Gong FF, Tao L, Cao HJ. A clinical study of the changes of condylar position in class II division 2 deep bite patients after orthodontic treatment. Shanghai Kou Qiang Yi Xue 2003; 12:334-7.

26. Fathallah M, El-Kenany W, Ismail H, Mowafy M. Three-dimentional evaluation of possible mandibular functional displacement in Class II division 2 malocclusion subjects. Egyptian Orthodontic Journal $2012 ; 42: 15-32$.

27. Demisch A, Ingervall B, Thüer U. Mandibular displacement in Angle Class II, division 2 malocclusion. Am J Orthod Dentofacial Orthop 1992; 102:509-18. 
Egyptian

Orthodontic Journal

28. Pullinger AG, Solberg WK, Hollender L, Petersson A. Relationship of mandibular condylar position to dental occlusion factors in an asymptomatic population. Am J Orthod Dentofacial Orthop 1987; 91:200-6.

29. Gianelly AA, Petras JC, Boffa J. Condylar position and Class II deep-bite, no-overjet malocclusions. Am J Orthod Dentofacial Orthop 1989; 96:428-32.

30. Ingervall $\mathrm{B}$. Relation between retruded contact, intercuspal, and rest positions of mandible in children with angle Class II, Division 2 malocclusion. Odontol Revy 1968;19:293-310.

31. Thüer U, Ingervall $B$, Bürgin $W$, Demisch A. No posterior mandibular displacement in Angle Class II, division 2 malocclusion as revealed with electromyography and sirognathography. Eur J Orthod 1992;14:162-71.

32. Ogawa T, Enciso R, Shintaku WH, Clark GT. Evaluation of cross-section airway configuration of obstructive sleep apnea. Oral Surg Oral Med Oral Pathol Oral Radiol Endod 2007;103:102-8.

33. Waitzman AA, Posnick JC, Armstrong DC, Pron GE. Craniofacial skeletal measurements based on computed tomography: Part I. Accuracy and reproducibility. Cleft Palate Craniofac J 1992;29: 112-7.

34. Aboudara C, Nielsen I, Huang JC, Maki K, Miller AJ, Hatcher D. Comparison of airway space with conventional lateral headfilms and 3-dimensional reconstruction from cone-beam computed tomography. Am J Orthod Dentofacial Orthop 2009; 135: 468-79.

35. Scarfe WC, Farman AG, Sukovic P. Clinical applications of cone-beam computed tomography in dental practice. J Can Dent Assoc 2006;72: 75-80.

36. Dupond WD, Plummer WD. Power and sample size calculations. A review and computer program. Control Clin Trials 1990;11:116-28.

37. Lagravère MO, Hansen L, Harzer W, Major PW. Plane orientation for standardization in 3-dimensional cephalometric analysis with computerized tomography imaging. Am J Orthod Dentofacial Orthop $2006 ; 129: 601-4$. 
38. Lowe AA, Ono T, Ferguson KA, Pae EK, Ryan CF, Fleetham JA. Cephalometric comparisons of craniofacial and upper airway structure by skeletal subtype and gender in patients with obstructive sleep apnea. Am J Orthod Dentofacial Orthop 1996;110:653-64.

39. Zhong Z, Tang Z, Gao X, Zeng XL. A comparison study of upper airway among different skeletal craniofacial patterns in non-snoring Chinese children. Angle Orthod 2010;80:267-74.

40. Williams PL, Warwick R, Dyson M, Bannister LH. Gray's Anatomy. 37th ed. London, United Kingdom: Churchill Livingstone; 1989: 1323-30.

41. Peppard PE, Young T, Palta M, Dempsey J, Skatrud J. Longitudinal study of moderate weight change and sleep-disordered breathing. JAMA 2000;284:3015-21.

42. Rubinstein I, Colapinto N, Rotstein LE, Brown IG, Hoffstein V. Improvement in upper airway function after weight loss in patients with obstructive sleep apnea. Am Rev Respir Dis 1988; 138:1192-5. 